\title{
Induction Motor Control Using Two Intelligent Algorithms Analysis
}

\author{
Moulay Rachid Douiri and Mohamed Cherkaoui \\ Mohammadia Engineering School, Department of Electrical Engineering, \\ Avenue Ibn Sina, B.P.765, Agdal-Rabat, Morocco \\ douirirachidahotmail.com
}

\begin{abstract}
The main drawbacks of classical direct torque control (C-DTC) are: the high torque and flux ripples and variable switching frequency. To overcome these problems, two intelligent control theories, namely fuzzy logic control (FLC) and neuro-fuzzy control (NFC) are introduced to replace the hysteresis comparators and lookup table of the C-DTC for induction motor drive. The effectiveness and feasibility of the proposed approaches have been demonstrated through computer simulations. A comparison study between the C-DTC, FL-DTC and NF-DTC has been made in order to confirm the validity of the proposed schemes. The superiority of the NF-DTC has been proved through comparative simulation results.
\end{abstract}

Keywords: direct torque control, fuzzy logic control, induction motor drive, neuro-fuzzy control.

\section{Introduction}

The direct torque control (DTC) was proposed by M.Depenbrock [1] and I.Takahashi [2]-[3] in 1985. The DTC is an entirely different approach to induction motor control that was developed to overcome field oriented control (FOC) relatively poor transient response and reliance on induction motor parameters [4]-[5]-[6]. Classical DTC is a popular torque control method for induction motors; therefore it is widely used in the area of the EV's motor control. Unfortunately the classical DTC algorithm has some significant limitations. It is difficult to distinguish between small and large variations in reference values. Also the variation of flux and torque over one sector is considerable [7]-[8]. Another problem is that adapting classical DTC to the confines of a DSP's sampling period can significantly deteriorate its performance [9]. To overcome these problems, two intelligent control theories, including fuzzy logic control (FLC) and neuro-fuzzy control (NFC) are introduced to replace the conventional comparators and selection table of direct torque control for induction motor drive.

Fuzzy logic can deal with vague concepts which have relative degrees of truth rather than just the usual true or false, it allows machines to perform jobs that in the past required a human being's ability to think and reason [10]-[11]. Conventional control systems express control contents by using control expressions such as equations or 
logical expressions. This requires a huge amount of information, and some kinds of control are difficult or impossible to model this way. Fuzzy logic control usually requires only one tenth or less of the information required by conventional methods [12]. This is also associated with a high reliability and fast processing speed. Fuzzy logic also deals effectively with a non-linear time varying system.

There is a rapidly growing interest in the fusion of fuzzy systems and neural networks to obtain the advantages of both methods while avoiding their individual drawbacks. The possibility of integration of these two paradigms has given rise to a rapidly emerging field of fuzzy neural networks. There are two distinctive approaches for fuzzy-neural integration. On the one hand, many paradigms that have been proposed simply view a fuzzy-neural system as any ordinary multilayered feed-forward neural network which is designed to approximate a fuzzy control algorithm [13]-[14]. On the other hand, there are those approaches which aim to realize the process of fuzzy reasoning and inference through the structure of a connectionist network [15]. Fuzzyneural networks are, in general, neural networks whose nodes have 'localized fields' which can be compared with fuzzy rules and whose connection weights can similarly be equated to input or output membership functions. The simplest attempt in merging of fuzzy logic and neural controllers is to make the neural networks (NN) learn the input-output characteristics of a fuzzy controller [16]. The NN in this case imitates the fuzzy controller but the only advantage is that the trained NN output has more smoothing robust actions than that of the fuzzy controller.

This paper is organized as follows: The principle of direct torque control is presented in the second part, the fuzzy logic direct torque control is developed in the third section, section four presents a neuro-fuzzy direct torque control, and the fifth part is devoted to illustrate the simulation performance of this control strategy, a conclusion and reference list at the end.

\section{Classical Direct Torque Control}

In a C-DTC motor drive, the machine torque and flux linkage are controlled directly without a current control. The principles of C-DTC can be explained by looking at the following torque and current equations of an induction motor:

$$
\begin{gathered}
T_{e}=\frac{3}{2} n_{p} \operatorname{Im}\left\{\vec{\lambda}_{s}^{*} \vec{i}_{s}^{*}\right\} \\
\overrightarrow{i_{s}}=\frac{1}{\sigma L_{s}} \vec{\lambda}_{s}-\frac{L_{m}}{\sigma L_{s} L_{r}} \vec{\lambda}_{r}, \text { with } \sigma=1-\frac{L_{m}^{2}}{L_{s} L_{r}}
\end{gathered}
$$

Substituting Eq. (1) in Eq. (2) we obtain:

$$
T_{e}=\frac{3}{2} n_{p} \frac{L_{m}}{\sigma L_{s} L_{r}}\left|\vec{\lambda}_{s}\right|\left|\vec{\lambda}_{r}\right| \sin \alpha
$$


where $\alpha$ is the angle between the stator and rotor flux linkage vectors [8]. The derivative of Eq. (3) can be represented approximately as:

$$
\frac{d T_{e}}{d t}=\frac{3}{2} n_{p} \frac{L_{m}}{\sigma L_{s} L_{r}}\left|\vec{\lambda}_{s}\right|\left|\vec{\lambda}_{r}\right| \frac{d \alpha}{d t} \cos \alpha
$$

The machine voltage equation can be represented and approximated in a short interval of $\Delta t$ as:

$$
\frac{d \vec{\lambda}_{s}}{d t}=\vec{v}_{s}-R_{s} \vec{i}_{s} \approx \vec{v}_{s} \text { implying } \Delta \vec{\lambda}_{s}=\vec{v}_{s} \Delta t
$$

The rotor flux linkage vector is sluggish in response to a voltage vector during $\Delta t$ as it is related to the stator flux linkage vector by a first order delay as in

$$
\frac{d \vec{\lambda}_{s}}{d t}+\left(\frac{L_{m}}{\sigma L_{s} L_{r}}-\frac{R_{r}}{L_{r}}-j \omega_{r}\right) \vec{\lambda}_{r}=\frac{R_{r} L_{m}}{\sigma L_{s} L_{r}} \vec{\lambda}_{s}
$$

Symbols:

$\begin{array}{ll}R_{s}, R_{r} & \text { stator and rotor resistance [S] } \\ i_{s d}, i_{s q} & \text { stator current } d q \text { axis [A] } \\ v_{s d}, v_{s q} & \text { stator voltage } d q \text { axis [V] } \\ L_{s}, L_{r} & \text { stator and rotor self inductance [H] } \\ L_{m} & \text { mutual inductance [H] } \\ \lambda_{s d}, \lambda_{s q} & d q \text { stator flux [Wb] } \\ \lambda_{r d}, \lambda_{r q} & d q \text { rotor flux [Wb] } \\ T_{e} & \text { electromagnetic torque [N.m] } \\ E_{T e} & \text { electromagnetic torque error [N.m] } \\ E_{\lambda s} & \text { stator flux error [Wb] } \\ \varphi_{s} & \text { stator flux angle [rad] } \\ \omega_{r} & \text { rotor speed [rad/sec] } \\ J & \left.\text { inertia moment [Kg.m }{ }^{2}\right] \\ n_{p} & \text { pole pairs } \\ \sigma & \text { leakage coefficient }\end{array}$

\section{$3 \quad$ Fuzzy Logic Direct Torque Control}

The structure of the switching table can be translated in the form of vague rules. Therefore, we can replace the switching table and hysteresis comparators by a fuzzy system whose inputs are the errors on the flux and torque denoted $E_{\lambda s}$ and $E_{T e}$ and the argument $\varphi$ of the flux. The output being the command signals of the voltage inverter $n$. The fuzziness character of this system allows flexibility in the choice of fuzzy sets of inputs and the capacity to introduce knowledge of the human expert. 
The $i^{\text {th }}$ rule $R_{i}$ can be expressed as:

$$
R_{i} \text { : if } E_{T e} \text { is } A_{i}, E_{\lambda s} \text { is } B_{i} \text {, and } \varphi \text { is } E_{i} \text {, then } n \text { is } N_{i}
$$

where $A_{i}, B_{i}$ and $C_{i}$ denote the fuzzy subsets and $N_{i}$ is a fuzzy singleton set.

The synthesized voltage vector $n$ denoted by its three components is the output of the controller.

The inference method used in this paper is Mamdani's [18] procedure based on min-max decision [19]. The firing strength $\eta_{i}$, for $i^{\text {th }}$ rule is given by:

$$
\eta_{i}=\min \left(\mu_{A_{i}}\left(E_{T_{e}}\right), \mu_{B_{i}}\left(E_{\lambda_{s}}\right), \mu_{C_{i}}(\varphi)\right)
$$

By fuzzy reasoning, Mamdani's minimum procedure gives:

$$
\mu_{N_{i}}^{\prime}(n)=\min \left(\eta_{i}, \mu_{N_{i}}(n)\right)
$$

where $\mu_{A}, \mu_{B}, \mu_{C}$, and $\mu_{N}$ are membership functions of sets $A, B, C$ and $N$ of the variables $E_{T e}, E_{\lambda s}, \varphi$ and $n$, respectively.

Thus, the membership function $\mu_{N}$ of the output $\mathrm{n}$ is given by:

$$
\mu_{N}(n)=\max _{i=1}^{72}\left(\mu_{N_{i}}^{\prime}(n)\right)
$$

We chose to share the universe of discourse of the stator flux error into two fuzzy sets, that of electromagnetic torque error in five and finally for the flux argument into seven fuzzy sets. However the number of membership functions (fuzzy set) for each variable can be increased and therefore the accuracy is improved. All the membership functions of fuzzy controller are given in Fig. 1.

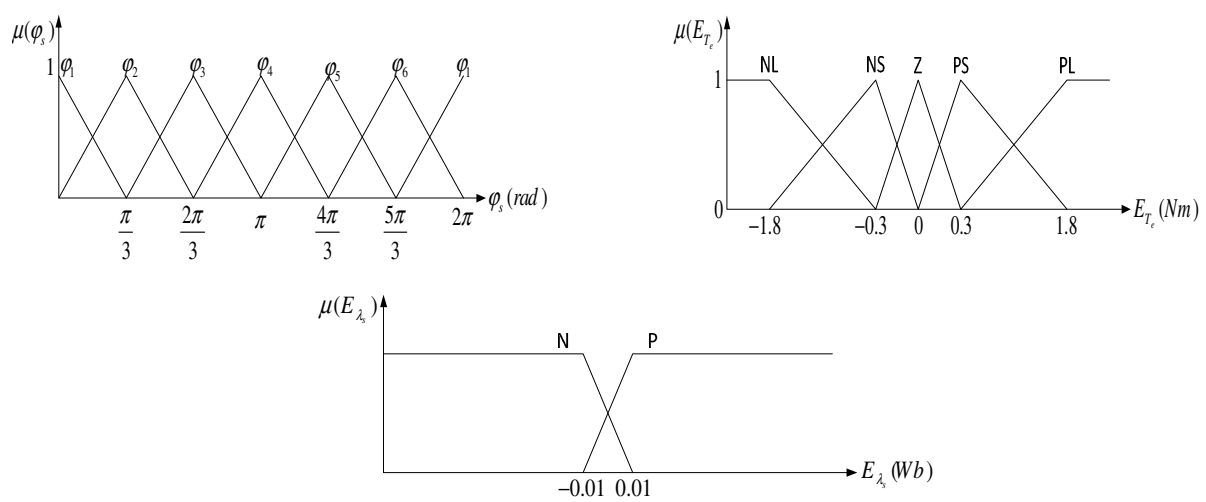

Fig. 1. Membership functions for fuzzy logic controller 
Table 1. Fuzzy rules

\begin{tabular}{clllllll}
\hline & & \multicolumn{7}{c}{$\varphi$} \\
$\mathrm{E}_{\lambda \mathrm{s}}$ & $\mathrm{E}_{\mathrm{Te}}$ & $\varphi_{1}$ & $\varphi_{2}$ & $\varphi_{3}$ & $\varphi_{4}$ & $\varphi_{5}$ & $\varphi_{6}$ \\
\hline \multirow{3}{*}{$\mathrm{PL}$} & $\mathrm{P}$ & $\mathrm{V}_{6}$ & $\mathrm{~V}_{2}$ & $\mathrm{~V}_{3}$ & $\mathrm{~V}_{1}$ & $\mathrm{~V}_{5}$ & $\mathrm{~V}_{4}$ \\
& $\mathrm{Z}$ & $\mathrm{V}_{4}$ & $\mathrm{~V}_{6}$ & $\mathrm{~V}_{2}$ & $\mathrm{~V}_{3}$ & $\mathrm{~V}_{1}$ & $\mathrm{~V}_{5}$ \\
& $\mathrm{~N}$ & $\mathrm{~V}_{5}$ & $\mathrm{~V}_{4}$ & $\mathrm{~V}_{6}$ & $\mathrm{~V}_{2}$ & $\mathrm{~V}_{3}$ & $\mathrm{~V}_{1}$ \\
& $\mathrm{P}$ & $\mathrm{V}_{6}$ & $\mathrm{~V}_{2}$ & $\mathrm{~V}_{3}$ & $\mathrm{~V}_{1}$ & $\mathrm{~V}_{5}$ & $\mathrm{~V}_{4}$ \\
$\mathrm{PS}$ & $\mathrm{Z}$ & $\mathrm{V}_{7}$ & $\mathrm{~V}_{0}$ & $\mathrm{~V}_{7}$ & $\mathrm{~V}_{0}$ & $\mathrm{~V}_{0}$ & $\mathrm{~V}_{0}$ \\
& $\mathrm{~N}$ & $\mathrm{~V}_{5}$ & $\mathrm{~V}_{4}$ & $\mathrm{~V}_{6}$ & $\mathrm{~V}_{2}$ & $\mathrm{~V}_{3}$ & $\mathrm{~V}_{1}$ \\
& $\mathrm{P}$ & $\mathrm{V}_{2}$ & $\mathrm{~V}_{3}$ & $\mathrm{~V}_{1}$ & $\mathrm{~V}_{5}$ & $\mathrm{~V}_{4}$ & $\mathrm{~V}_{6}$ \\
$\mathrm{NS}$ & $\mathrm{Z}$ & $\mathrm{V}_{0}$ & $\mathrm{~V}_{7}$ & $\mathrm{~V}_{0}$ & $\mathrm{~V}_{7}$ & $\mathrm{~V}_{0}$ & $\mathrm{~V}_{7}$ \\
& $\mathrm{~N}$ & $\mathrm{~V}_{1}$ & $\mathrm{~V}_{5}$ & $\mathrm{~V}_{4}$ & $\mathrm{~V}_{6}$ & $\mathrm{~V}_{2}$ & $\mathrm{~V}_{3}$ \\
& $\mathrm{P}$ & $\mathrm{V}_{2}$ & $\mathrm{~V}_{3}$ & $\mathrm{~V}_{1}$ & $\mathrm{~V}_{5}$ & $\mathrm{~V}_{4}$ & $\mathrm{~V}_{6}$ \\
$\mathrm{NL}$ & $\mathrm{Z}$ & $\mathrm{V}_{3}$ & $\mathrm{~V}_{1}$ & $\mathrm{~V}_{5}$ & $\mathrm{~V}_{4}$ & $\mathrm{~V}_{6}$ & $\mathrm{~V}_{2}$ \\
& $\mathrm{~N}$ & $\mathrm{~V}_{1}$ & $\mathrm{~V}_{5}$ & $\mathrm{~V}_{4}$ & $\mathrm{~V}_{6}$ & $\mathrm{~V}_{2}$ & $\mathrm{~V}_{3}$ \\
\hline
\end{tabular}

\section{Neuro-Fuzzy Direct Torque Control}

In this section, the Neuro-Fuzzy (NF) model is built using the multilayer fuzzy neural network shown in Fig.1. The controller has a total of five layers as proposed by Lin and Lee [17], with two inputs (stator flux error $E_{\psi s}$, electromagnetic torque error $E_{T e}$ ) and a single output (voltage space vector) is considered here for convenience. Consequently, there are two nodes in layer 1 and one node in layer 5. Nodes in layer 1 are input nodes that directly transmit input signals to the next layer. The layer 5 is the output layer. The nodes in layers 2 and 4 are "term nodes" and they act as membership functions to express the input/output fuzzy linguistic variables. A bell-shaped function is adopted to represent a membership function, in which the mean value $p$ and the variance $\chi$ are adjusted through the learning process. The two fuzzy sets of the first and the second input variables consist of $k_{1}$ and $k_{2}$ linguistic terms, respectively. The linguistic terms are numbered in descending order in the term nodes; hence, $k_{l}+k_{2}$ nodes and $n_{3}$ nodes are included in layers 2 and 4, respectively, to indicate the input/output Linguistic variables.

Layer 1: Each node in this layer performs a MF:

$$
y_{i}^{1}=\mu_{A i}\left(x_{i}\right)=\exp \left\{-\left[\left(\frac{x_{i}-c_{i}}{a_{i}}\right)^{2}\right]^{b_{i}}\right\}
$$

where $x_{i}$ is the input of node $i, A_{i}$ is linguistic label associated with this node and $\left(a_{i}, b_{i}, c_{i}\right)$ is the parameter set of the bell-shaped MF. $y_{i}{ }^{l}$ specifies the degree to which the given input belongs to the linguistic label $A_{i}$, with maximum equal 1 and minimum equal to 0 . As the values of these parameters change, the bell-shaped function varies accordingly, thus exhibiting various forms of membership functions. In 
fact, any continuous and piecewise differentiable functions, such as trapezoidal or triangular membership functions, are also qualified candidates for node functions in this layer.

Layer 2 - Every node in this layer represents the firing strength of the rule. Hence, the nodes perform the fuzzy AND operation:

$$
y_{i}^{2}=w_{i}=\min \left(\mu_{A \lambda_{s}}\left(E_{\lambda_{s}}\right), \mu_{B T_{e}}\left(E_{T_{e}}\right), \mu_{C \varphi_{s}}\left(\varphi_{s}\right)\right)
$$

Layer 3 - The nodes of this layer calculate the normalized firing strength of each rule:

$$
y_{i}^{3}=\bar{w}_{i}=\frac{w_{i}}{\sum_{i=1}^{n} w_{i}}
$$

Layer 4 - Output of each node in this layer is the weighted consequent part of the rule table:

$$
y_{i}^{4}=\bar{w}_{i} f_{i}=\bar{w}_{i}\left(p_{i} E_{\lambda_{s}}+q_{i} E_{T_{e}}+m_{i} \varphi_{s}+n_{i}\right)
$$

where $\bar{w}_{i}$ is the output of layer 3 , and $\left\{p_{i}, q_{i}, m_{i}, n_{i}\right\}$ is the parameter set. Which determine the $i^{\text {th }}$ component of vector desired voltage. By multiplying weight $y_{i}$ by voltage continuous $V$ side of the inverter according to Eq. (15):

$$
V^{*}=y_{i} V
$$

Layer 5 - The single node in this layer computes the overall output as the summation of all incoming signals:

$$
y_{i}^{5}=\sum_{i=1}^{n} \bar{w}_{i} f_{i}
$$

Which determine the vector reference voltage $v_{s}{ }^{*}$ (see Fig. 4), from Eq. (17):

$$
v_{s}^{*}=\sum_{i=1}^{9} y_{i} V e^{j \xi_{i}^{*}}
$$

The angle $\xi$ is obtained from the actual angle of stator flux $\varphi_{s}$ and angle increment $d \varphi_{i}$ given by this Eq. (18):

$$
\xi_{i}=\varphi_{s}+d \varphi_{i}
$$

$y_{i}(i=1 . .9)$ are the output signals order $i$ of the third layer respectively. 


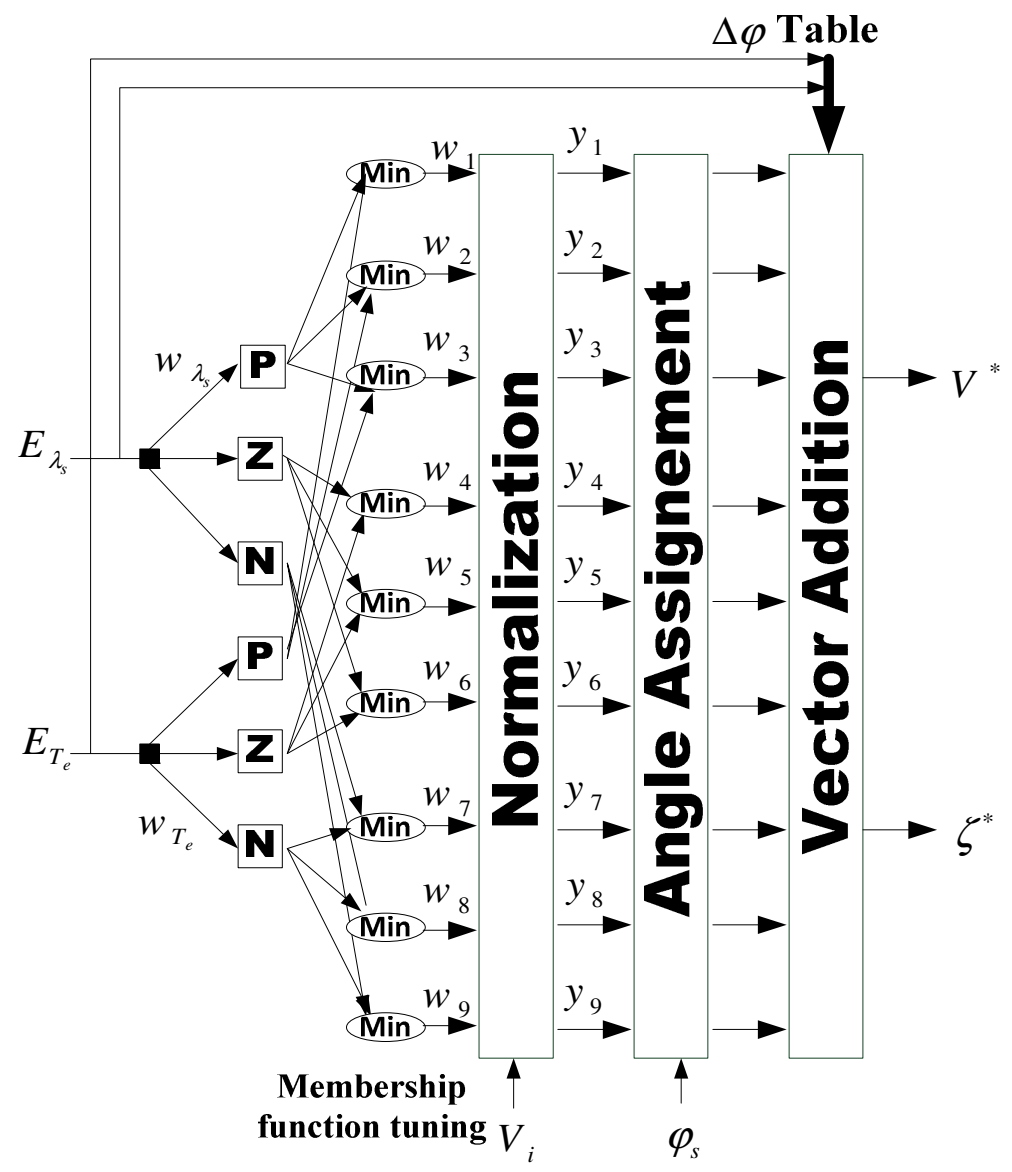

Fig. 2. Topology of the neuro-fuzzy model used

Table 2. Parameters setting for ANFIS model

\begin{tabular}{ll}
\hline ANFIS Setting & Details \\
\hline Input variables & Electromagnetic torque error, and stator flux error \\
Output response & Space voltage vector \\
Type of input MFs & Generalized Bell MF \\
Number of MFs & $2,3,4$ and 5 \\
Type of output MFs & Linear and constant \\
Type inference & Linear Sugeno \\
Optimization Method & Hybrid of the least-squares and the back propagation \\
& gradient descent method. \\
Number of data & 520 \\
Epochs & 1000 \\
\hline
\end{tabular}




\section{$5 \quad$ Simulation Results}

To compare and verify the proposed techniques in this paper, a digital simulation based on Matlab/Simulink program with a Fuzzy Logic Toolbox and ANFIS Toolbox is used to simulate the NF-DTC and FL-DTC, as shown in Fig. 3. The block diagram of a C-DTC/FL-DTC/NF-DTC controlled induction motor drive fed by a 2-level inverter is shown in Fig. 3. The induction motor used for the simulation studies has the following parameters:

Rated power $=7.5 \mathrm{~kW}$, Rated voltage $=220 \mathrm{~V}$, Rated frequency $=60 \mathrm{~Hz}, R_{r}=$ $0.17 \Omega, R_{s}=0.15 \Omega, L_{r}=0.035 \mathrm{H}, L_{s}=0.035 \mathrm{H}, L_{m}=0.0338 \mathrm{H}, J=0.14 \mathrm{~kg} \cdot \mathrm{m}^{2}$.

Figs. 4(a), 4(b) and 4(c) show the torque response of the C-DTC, FL-DTC and NFDTC respectively with a torque reference of [20-10-15]Nm. While Figs. 4(a'), 4(b') and 4(c') show the flux response of the C-DTC, FL-DTC and NF-DTC respectively with a stator flux reference of $1 \mathrm{~Wb}$.

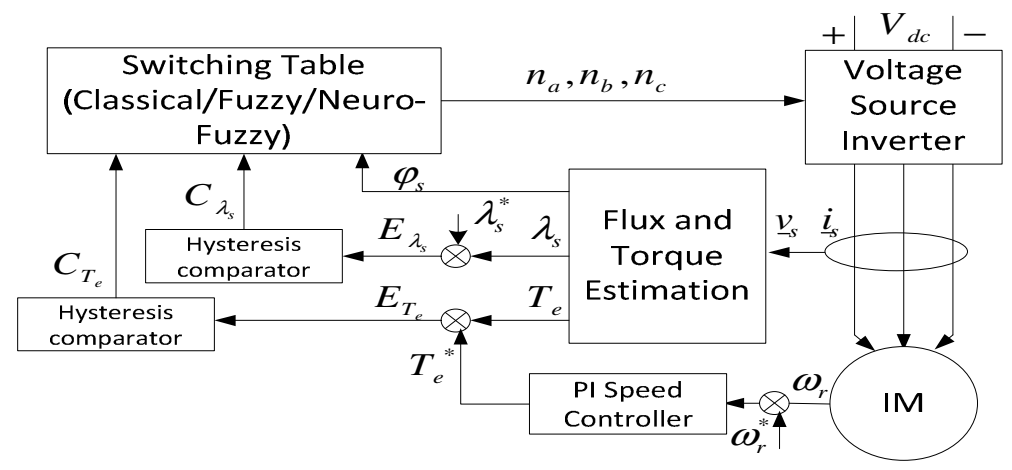

Fig. 3. General configuration of C-DTC/FL-DTC/NF-DTC scheme

Table 3 represents the comparative results in both stator flux and torque ripples percentage for C-DTC, FL-DTC and NF-DTC. The steady state response for the torque in NF-DTC is faster and provided more accuracy compared to other control strategies presented in this paper.

Table 3. Comparative study of C-DTC, FL-DTC and NF-DTC

\begin{tabular}{|c|c|c|c|c|}
\hline Control strategies & $\begin{array}{c}\text { Torque ripple } \\
(\%)\end{array}$ & $\begin{array}{c}\text { Flux ripple } \\
(\%)\end{array}$ & $\begin{array}{c}\text { Rise time } \\
(\mathrm{sec})\end{array}$ & $\begin{array}{c}\text { Setting time } \\
(\mathrm{sec})\end{array}$ \\
\hline C-DTC & 10.6 & 2.3 & 0.009 & 0.01 \\
\hline FL-DTC & 3.9 & 2.1 & 0.007 & 0.0085 \\
\hline NF-DTC & 2.7 & 1.4 & 0.005 & 0.0071 \\
\hline
\end{tabular}




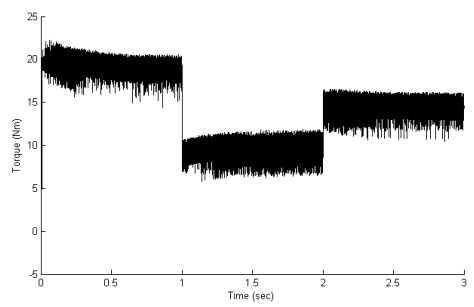

a

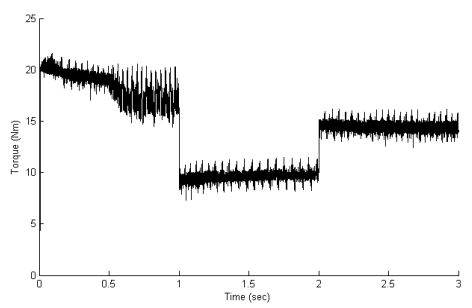

b

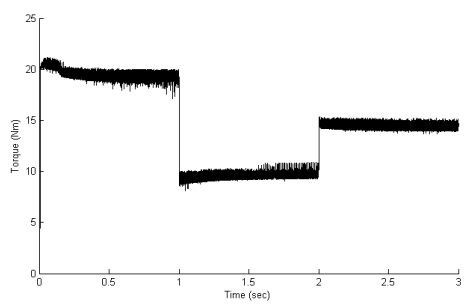

C

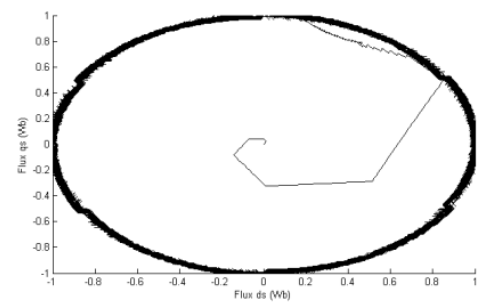

a'

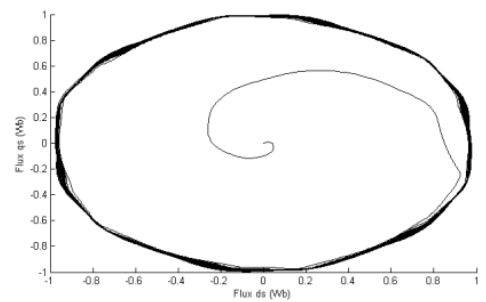

b'

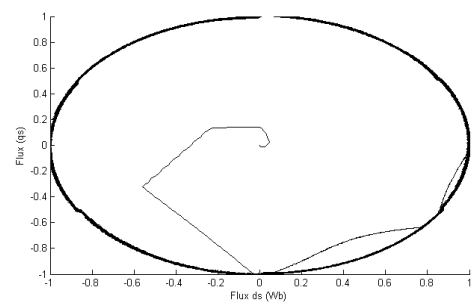

c'

Fig. 4. (a), (b) and (c) torque response of C-DTC, FL-DTC and NF-DTC respectively, (a'), (b') and (c') Stator flux trajectory response of C-DTC, FL-DTC and NF-DTC respectively

\section{Conclusions}

Two various intelligent torque control schemes worth knowing fuzzy logic direct torque control, and neuro-fuzzy direct torque control have been evaluated for induction motor control and which have been compared with the conventional direct torque control technique. A better precision in the torque and flux responses was achieved with the NF-DTC method with greatly reduces the execution time of the controller; hence the steady-state control error is almost eliminated. The application of neural network techniques simplifies hardware implementation of direct torque control and it is envisaged that NF-DTC induction motor drives will gain wider acceptance in future. 


\section{References}

1. Depenbrock, M.: Direct Self-Control (DSC) of Inverter-Fed Induction Machine. IEEE Transaction on Power Electronics 3(4), 420-429 (1988)

2. Takahashi, I., Noguchi, T.: New Quick-Response and High-Efficiency Control Strategy of an Induction Motor. IEEE Transactions on Industry Applications IA 22(5), 820-827 (1986)

3. Noguchi, T., Yamamoto, M., Kondo, S., Takahashi, I.: Enlarging Switching Frequency in Direct Torque-Controlled Inverter by Means of Dithering. IEEE Transaction on Industry Applications 35(6), 1358-1366 (1999)

4. Casadei, D., Profumo, F., Serra, G., Tani, A.: FOC and DTC: Two Viable Schemes for Induction Motors Torque Control. IEEE Transactions on Power Electronics 17(5), 779-787 (2002)

5. Le-Huy, H.: Comparison of Field-Oriented Control and Direct Torque Control for Induction Motor Drives. In: Conference Record - IAS Annual Meeting, vol. 2, pp. 1245-1252. IEEE Industry Applications Society (1999)

6. Vaez-Zadeh, S., Jalali, E.: Combined Vector Control and Direct Torque Control Method for High Performance Induction Motor Drives. Energy Conversion and Management 48(12), 3095-3101 (2007)

7. Lai, Y.-S., Chen, J.-H.: A New Approach to Direct Torque Control of Induction Motor Drives for Constant Inverter Switching Frequency and Torque Ripple Reduction. IEEE Transactions on Energy Conversion 16(3), 220-227 (2001)

8. Wei, X., Chen, D., Zhao, C.: Minimization of Torque Ripple of Direct-Torque Controlled Induction Machines by Improved Discrete Space Vector Modulation. Electric Power Systems Research 72(2), 103-112 (2004)

9. Shyu, K.-K., Lin, J.-K., Pham, V.-T., Yang, M.-J., Wang, T.-W.: Global Minimum Torque Ripple Design for Direct Torque Control of Induction Motor Drives. IEEE Transactions on Industrial Electronics 57(9), art. no. 5371908, 3148-3156 (2010)

10. Andrews, P.B.: An Introduction to Mathematical Logic and Type Theory: To Truth Through Proof. Kluwer, Dordrecht (2002)

11. Novák, V.: Reasoning About Mathematical Fuzzy Logic and its Future. Fuzzy Sets and Systems 192, 25-44 (2012)

12. Verbruggen, H.B., Babuška, R.: Fuzzy Logic Control: Advances in Applications. World Scientific Publishing Co Pte Ltd. (1999)

13. Wang, L.-X., Mendel, J.M.: Fuzzy Basis Functions, Universal Approximation, and Orthogonal Least-Squares Learning. IEEE Transactions on Neural Networks 3(5), 807-814 (1992)

14. Hsu, C.-H., Lin, P.-Z., Lee, T.-T., Wang, C.-H.: Adaptive Asymmetric Fuzzy Neural Network Controller Design via Network Structuring adaptation. Fuzzy Sets and Systems 159(20), 2627-2649 (2008)

15. Takagi, H., Suzuki, N., Koda, T., Kojima, Y.: Neural Networks Designed on Approximate Reasoning Architecture and Their Applications. IEEE Transactions on Neural Networks 3(5), 752-760 (1992)

16. Nauck, D., Klawonn, F., Kruse, R.: Foundations of Neuro-Fuzzy Systems, 1st edn. John Wiley (1997)

17. Lin, C.-T., Lee, C.S.G.: Neural-Network-Based Fuzzy Logic Control and Decision System. IEEE Transactions on Computers 40(12), 1320-1336 (1991) 